\title{
Rare Benign Tumors of the Liver: Still Rare?
}

\author{
Gaetano Bertino • Annalisa Ardiri • Shirin Demma - Stefano GiuseppeCalvagno • \\ Adriana Toro • Elisa Basile • Davide Campagna • Giorgia Ferraro • Evelise Frazzetto • \\ Maria Proiti • Giulia Malaguarnera • Nicoletta Bertino • Mariano Malaguarnera • \\ Michele Malaguarnera • Maria Domenica Amaradio • Gabriele Pricoco • Isidoro Di Carlo
}

Published online: 9 February 2014

(C) Springer Science+Business Media New York 2014

\begin{abstract}
Background Benign liver tumors are common. They do not spread to other areas of the body, and they usually do not pose a serious health risk. In fact, in most cases, benign liver tumors are not diagnosed because patients are asymptomatic. When they are detected, it's usually because the person has had medical imaging tests, such as an ultrasound (US), computed tomography (CT) scan, or magnetic resonance imaging (MRI), for another condition.

Materials and methods A search of the literature was made using cancer literature and the PubMed, Scopus, and Web of Science (WOS) database for the following keywords: "hepatic benign tumors", "hepatic cystic tumors", "polycystic liver disease", "liver macroregenerative nodules", "hepatic mesenchymal hamartoma", "hepatic angiomyolipoma", "biliary cystadenoma", and "nodular regenerative hyperplasia".

Discussion and conclusion Hepatocellular carcinoma (HCC) is one of the most common malignant tumors in some areas of the world; there is an increasing incidence worldwide. Approximately 750,000 new cases are reported per year. More
\end{abstract}

G. Bertino $(\bowtie) \cdot$ A. Ardiri $\cdot$ S. Demma $\cdot$ S. GiuseppeCalvagno $\cdot$

E. Basile $\cdot$ D. Campagna $\cdot$ G. Ferraro $\cdot$ E. Frazzetto $\cdot$ M. Proiti $\cdot$

M. D. Amaradio $\cdot$ G. Pricoco

Hepatology Unit, Department of Medical and Pediatric Science, University of Catania, Policlinic-Via S. Sofia n. 78, 95123 Catania, Italy

e-mail: gaetanobertinounict@libero.it

\section{A. Toro · I. Di Carlo}

Department of Surgical Sciences, Organ Transplantation and

Advanced Technologies, University of Catania, Catania, Italy

G. Malaguarnera $\cdot \mathrm{M}$. Malaguarnera $\cdot \mathrm{M}$. Malaguarnera

Research Centre 'The Great Senescence", University of Catania,

Catania, Italy

N. Bertino

Faculty of Pharmacy, University of Catania, Catania, Italy than $75 \%$ of cases occur in the Asia-Pacific region, largely in association with chronic hepatitis B virus (HBV) infection. The incidence of HCC is increasing in the USA and Europe because of the increased incidence of hepatitis $\mathrm{C}$ virus (HCV) infection. Unlike the liver HCC, benign tumors are less frequent. However, they represent a chapter always more interesting of liver disease. In fact, a careful differential diagnosis with the forms of malignant tumor is often required in such a way so as to direct the patient to the correct therapy. In conclusion, many of these tumors present with typical features in various imaging studies. On occasions, biopsies are required, and/or surgical removal is needed. In the majority of cases of benign hepatic tumors, no treatment is indicated. The main indication for treatment is the presence of significant clinical symptoms or suspicion of malignancy or fear of malignant transformation.

Keywords Hepatic benign tumors - Hepatic cystic tumors . Polycystic liver disease $\cdot$ Liver macro-regenerative nodules Hepatic mesenchymal hamartoma $\cdot$ Hepatic angiomyolipoma $\cdot$ Biliary cystadenoma $\cdot$ Nodular regenerative hyperplasia

\section{Cystic Tumors}

Simple Cyst

Hepatic cyst lesions are relatively common and usually found as a mere coincidence due to the improvement in radiographic technology and increased use of abdominal imaging techniques such as ultrasonography (USG), computed tomography (CT), and magnetic resonance imaging (MRI) $[1,2]$. In most cases, simple hepatic cysts follow a benign course so they are usually incidental findings. It's more often to find these lesions in women that in men, among which they can 
also be more frequently symptomatic [3]. Presentations occur most frequently in the fifth decade [4]. Usually, they are congenital due to an abnormal and excessive intrahepatic bile ducts developed during embryogenesis. These ducts can be obstructed or have no connection with extrahepatic ducts. The cysts are lined by simple cuboidal epithelium and thin underlying rim of fibrous stroma. They contain clear fluid with water and electrolyte content similar to the serum [5]. Simple cysts are often single, but multiple cysts are also known to occur. Every cyst is nonloculated. Early estimates of the incidence were generated from autopsy studies $(0.14$ $0.53 \%$ ) [6-8], but with the modern techniques, simple cysts are now detected in $2.5-5 \%$ of the population [9-11]. Only $15-16 \%$ of these lesions are symptomatic $[10,12]$.

\section{Clinical Features}

Simple cysts are usually asymptomatic, but in a small fraction of patients, symptoms such as abdominal pain, early satiety, nausea, and vomiting can be present as a result of a mass effect [13] and related to the size of the cyst. Complications are rare. The compression of the biliary system can result in jaundice, and the rupture in the abdominal cavity can result in infections, hemorrhage, and biliary communications [14]. Physical examination can reveal hepatomegaly or a palpable abdominal mass.

\section{Diagnostic Evaluation}

The aim of the diagnostic evaluation is to diagnose simple cysts, excluding cystadenomas, cystadenocarcinoma, hydatid cysts, and polycystic liver disease. Moreover, it's necessary to exclude hemorrhage, biliary communication, and secondary carcinoma in the cyst. Laboratory findings are usually normal, but in a minority of patients, it can be found a raised serum gamma-glutamyl transferase (gGT). Also, cancer antigen 19.9 (CA 19.9) may be elevated for its expression in the simple cyst inner epithelial lining so it is not helpful in the differential diagnosis of intracystic hemorrhage [15-20]. The diagnosis of a simple cyst is based on the following ultrasonographic criteria: it has to be anechoic, unseptate, with a sharp smooth border, with a strong posterior wall echo, and spherical or oval shaped with a relative accentuation of echoes beyond the cyst [21]. USG has a reported sensitivity and specificity of $90 \%$ [22], and it's not accompanied with a radiation load, and it's non-invasive and cost-effective. At the CT, it appears as a defined homogeneous hypodense lesion, while at the MRI, it has a low signal intensity in the T1-weighted sequences and a high signal intensity, that does not enhance after contrast injection, in the $\mathrm{T} 2$ weighted sequences [23, 24]. CT can be useful to localize the cyst, identify the amount of liver tissue around the cyst and its position in relation to other nearby structures if it is essential to decide an appropriate treatment when necessary [25]. In the presence of intracystic bleeding, MRI is considered instead to be more specific compared to USG and CT [26]. Because of the radiation load of the CT and of the significantly higher cost of both the techniques, ultrasound remains to be the better imaging modality for diagnosing simple cysts that does not need an intervention.

\section{Management}

It is important to establish if cysts are causing the symptoms. If cysts are asymptomatic, conservative management is appropriate. This expectant approach is based on the observation. Conventional management used to be either aspiration or open surgery but while aspiration is followed by a high recurrence rate [27], surgical intervention can be associated with significant morbidity and mortality. The aims of therapy are to excise or obliterate the cyst completely or partially and to prevent recurrence. In case of doubt, a trial aspiration in order to assess the relief of symptoms can be attempted [25]. Sclerotherapy with alcohol after aspiration has been employed with success, and, more recently, minocycline hydrochloride has been effectively used. Prior to alcohol sclerosis, it's necessary to rule out biliary communication and malignancy. The cyst is completely emptied by a pigtail catheter, and a pre procedure injection of a contrast agent is used to exclude communications. ERCP (endoscopic retrograde cholangiopancreatography) is useful in cases where the aspirate is bile stained. Then, a volume of alcohol equal to $25 \%$ of the drained fluid is instilled into the cyst and left for at least $10 \mathrm{~min}[26,27]$. Alcohol strength is still not standardized. It's recommended to not exceed more than $100 \mathrm{ml}$ of alcohol at one time, and it may be necessary to repeat the procedure two or more times. Minor complications consist of mild pain, nausea, vomiting, and transient increase in temperature. If severe pain occurs, it can be the result of leakage of alcohol around the catheter $[25,28,29]$. Pain can be avoided by the use of lignocaine into the cyst before instilling alcohol. Minocycline $\mathrm{HCl}$ is a cytotoxic agent with an acid $\mathrm{PH}$ that is effective in destroying the epithelium at a dose of $100-500 \mathrm{mg}$ diluted in $10 \mathrm{ml}$ of normal saline solution. Mild pain can be experienced as a minor side-effect of this procedure. The solution is left in situ for about 10-15 $\mathrm{min}$ [30]. The complete surgical excision of the cysts, segmental hepatic resections, and lobectomies lead to a high incidence of complications and death [29, 31]. Laparoscopic fenestration of hepatic cysts has been attempted with satisfactory results. The principle is to deroof the cysts and allow them to drain freely into the peritoneal cavity. The fluid is subsequently reabsorbed because of its composition similar to serum [32]. If a biliary communication is present, cystoenterostomy should be preferred but it's associated with the risk of ascending infections [33-35]. Because of the excellent overall results obtained with 
laparoscopic unroofing of the simple cysts, this should be considered the procedure of choice for treatment of these lesions [36].

\section{Polycystic Liver Disease}

Polycystic liver diseases (PCLDs) are genetic disorders characterized by the progressive development of multiple cysts in the liver parenchyma which originate from biliary epithelium. They are caused by genetic defects in proteins present in the cellular cilium that damage the normal cholangiocyte signaling [37]. PCLDs include various entities, different for their pathology, inheritance pattern, and clinical features.

\section{There are Different Clinical Presentations}

Polycystic liver associated with autosomal-dominant polycystic kidney disease (ADPKD) is the most frequent: it occurs in 1:500-1000 individuals; it presents multiple cysts in kidneys, liver, and pancreas, and it may be associated with vascular abnormalities. In this case, liver function is well preserved, portal hypertension is rare, and the patient is asymptomatic [38] until adulthood, when it often leads to dialysis and renal transplantation.

The "isolated" polycystic liver disease (PCLD) is a common disease that, for a long time, was considered a phenotypic variant of ADPKD. The presence of some cysts in the kidney may render difficult the differentiation between ADPKD and PCLD, so the identification of specific gene mutation is necessary to reveal PCLD as a distinct disease [39].

Rare polycystic pathologies are: fibropolycystic diseases, as congenital hepatic fibrosis (CHF), Caroli disease (CD), and autosomal-recessive polycystic kidney disease (ARPKD). CD and CHF are characterized by excessive peribiliary fibrosis which leads to recurrent acute cholangitis (CD) and severe portal hypertension (CHF) [2]. In particular, Caroli's disease has two variants: Caroli disease, characterized only by ectasias of intrahepatic bile ducts and Caroli syndrome, in which congenital ductal dilatation is associated with hepatic fibrosis, portal hypertension, choledochal cysts, and renal disease [40, 41].

Finally, ARPKD is a rare condition that occurs in 1:20,000 live births [42] with a high mortality rate. In contrast with ADPKD, the majority of patients are infants. It causes cystic kidneys in the developing fetus in utero and half of the patients have, in the neonatal period, enlarged, cystic kidneys and pulmonary hypoplasia [43]. Moreover, affected patients also have dilated bile ductules and peribiliary fibrosis.
Genetic and Physiopathology

Cystogenesis is the result of alteration of ciliary structure and of its functions [44]. In particular, the primary cilium is involved: a solitary, non-motile, long, tubular organelle extending from the apical plasma membrane of the cell $[45,46]$ particularly abundant in cholangiocytes.

ADPKD is associated with mutations in 2 genes: PKD1 or PKD2, encoding polycystin-1 (PC1) and polycystin-2 (PC2), respectively. These proteins are normally localized in primary cilia [47]. $\mathrm{PC} 1$ is a mechanoreceptor that, sensing changes in apical flow, stimulates PC2 [48] and cleaves fragments of the PC1 cytoplasmic tail, translocates to the nucleus, and prevents $\beta$-catenin transcriptional activity, bending it $[48,49] . \mathrm{PC} 2$ is a transmembrane protein that functions as a non-selective $\mathrm{Ca}^{2+}$ channel. PC2 responds to bending of the cilium, biliary osmolarity, or other mechanical and chemical stimuli, participates in receptor-operated $\mathrm{Ca} 2$-signaling, depending on its interactions with $\mathrm{PC} 1$, and regulates cytoplasmic and endoplasmic reticulum (ER)-Ca2-homeostasis [50, 51].

Moreover, it has been demonstrated that $\mathrm{PC} 1$ and $\mathrm{PC} 2$ have a central role in the modulation of cholangiocyte growth. It suggests that primary cilia may act as a sensor of cell injury, activating a proliferative response to trigger the reparative processes [52]. In fact, PKD1 cystic epithelial cells are more sensitive to the mitogenic effect of growth factors and cAMP in vitro, thanks to Ras and Raf activity [53]. In addition, in patients with ADPKD, the tubular epithelium appears to switch from an absorptive to a secretory phenotype [54]. It is important to subline that the severe form of the disease is only evident in mice in which both PKD alleles are disrupted, while heterozygous PKD mice develop only a few cysts by adulthood. This shows that "two hits" are required for development of the cystic phenotype. So, even if ADPKD is phenotypically autosomal dominant, at the cellular level, it is likely to be a "molecular recessive" disease [55].

The genes responsible for PCLD are PRKCSH and SEC63, encoding for proteins expressed in the ER that are associated with the processing of glycoproteins in the ER. PRKCSH encodes for hepatocystin that regulates the correct localization in the ER of enzymes involved in the quality control of newly synthesized glycoproteins. The SEC63 gene encodes for a component of the regulating system of translocation and folding of newly synthesized membrane glycoproteins [56, 57]. ARPKD, CD, and CHF are consequences of mutations in the PKHD1 gene which encodes for fibrocystin, a large transmembrane protein, with several functions such as proliferation, secretion, terminal differentiation, and tubulogenesis [58].

Summarizing, the principal mechanism of cystogenesis are: increased cell proliferation and apoptosis; enhanced fluid secretion; abnormal cell-matrix interaction; and alterations in cell polarity [47]. 
Autosomal Dominant PCLD (ADPCLD)

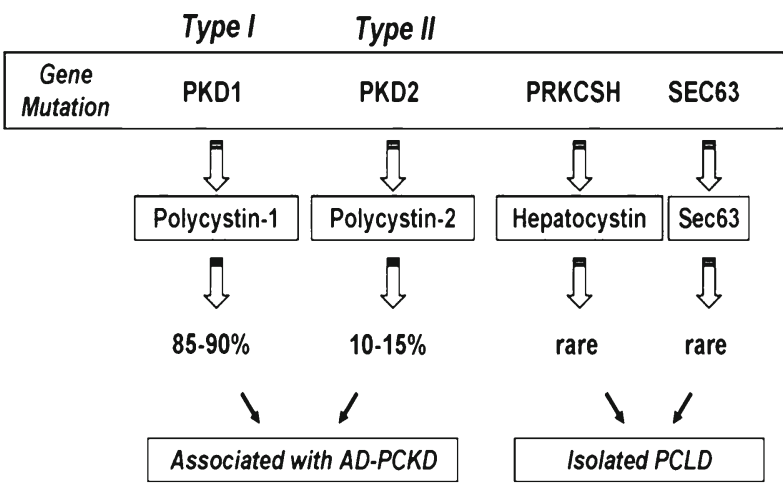

Regarding the pathological anatomy in ADPKD and PCLD, liver cysts are into the liver parenchyma, without connection to the biliary tree, which appears anatomically intact, while in fibropolycystic diseases, liver cysts are connected to the biliary tree, which appear distorted by the abundant fibrotic tissue [38].

\section{Clinical Presentation}

Most of the patients with polycystic liver are clinically asymptomatic. PCLDs are usually diagnosed incidentally during a routine (usually radiological) examination. Symptoms are typically caused by mechanical compression of adjacent structures as a result of the massive enlargement of the liver and include abdominal pain, abdominal distension, dyspepsia, gastro-esophageal reflux, early satiety, dyspnea, and mechanical back pain.

The majority of symptomatic patients with PCLDs are female [59] and are aged approximately 50 years (range 2384 years) at the time of presentation, which suggests a hormonal component to the development of PLD [60]. Indeed, risk factors for development of severe PCLDs are prior use of exogenous estrogens and multiple pregnancies [61]. This observation suggests that women with this disease should avoid estrogen replacement therapy [62].

The most common complications are cyst infection and hemorrhage that typically only occur in patients with severe PCLDs. A cyst infection is usually characterized by acute pain or tenderness in the right upper quadrant, malaise, fever with chills, and leukocytosis. This acute presentation should be diagnosed and treated early to prevent progression to bacteremia, sepsis, and death. In patients with cyst, infection has been reported to have a morbidity and mortality rate of $2 \%$ and $3 \%$, respectively [63]. Thus, there should be early institution of antibiotics and a drainage procedure. A bleeding cyst results in a sudden, severe pain that is self-limiting and can be managed with analgesics. In rare cases, cysts at certain
Autosomal Recessive PCLD (ARPCLD)

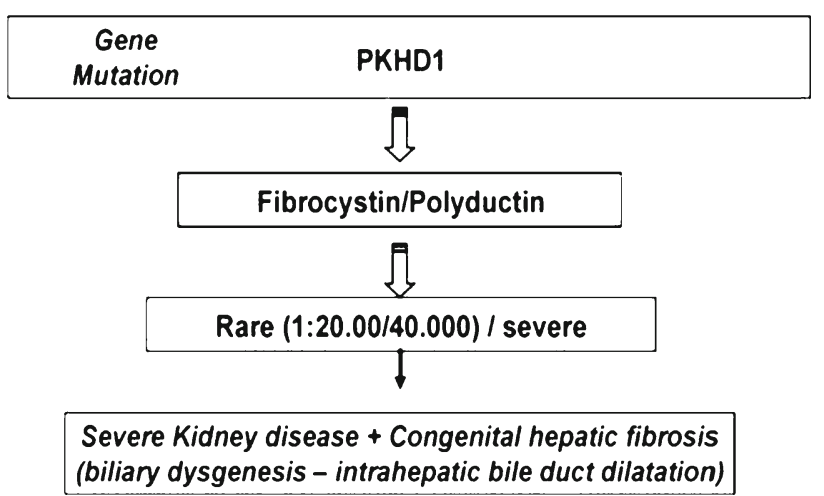

locations can cause hepatic venous outflow obstruction, inferior vena cava syndrome, and portal hypertension. Rarely, jaundice occurs as a result of cystic compression of the biliary system. This manifests as a result of the normal progression of cyst growth and compression of the common hepatic duct or common bile duct [64].

Extrahepatic abnormalities in PCLDs have been described. Increased frequencies of vascular complications were observed in patients with ADPKD, including valvular disease, especially mitral valve prolapse and mitral valve incompetence [65]. Although the occurrence of intracranial aneurysm has also been described previously, it has been recently observed in PCLD patients $[60,66]$. However, patients with isolated PCLD tend to have lower rates of extrahepatic manifestations.

\section{Diagnosis}

In general, there are no abnormalities in levels of liver enzymes in the majority of patients because parenchymal liver volume and liver synthesis capacity are preserved during all stages of PCLDs. However, an increase in serum levels of $\gamma$ glutamyltransferase, alkaline phosphatase, and to a less extent of aspartate aminotransferase (AST) can be found in patients with advanced disease. Renal function remains intact in PCLD, whereas ADPKD patients show a rise in serum creatinine due to impaired renal function [25]. Total bilirubin level is usually normal but can increase in the case of compression of the common bile duct by a cyst. Levels of carbohydrate antigen 19.9 (CA 19.9) are raised in patients with PLD, and recently, Wanders and coauthors show that serum concentration of CA19-9 positively correlates with the liver volume [67]. These findings suggest that CA 19.9 might be useful as a diagnostic or follow-up biomarker [15-18]. Mutation analysis for PCLD (PRKCSH and SEC63) has limited utility and is rarely performed in routine clinical practice, as it is not needed for clinical decision-making for these patients. 
PCLDs are diagnosed by imaging studies, including abdominal ultrasound, CT-scan, and magnetic resonance imaging (MRI). Ultrasound is generally preferred because of its low cost, easy accessibility, and absence of radiation exposure. However, CT and MRI are more sensitive and specific in detecting the presence and size of liver cysts.

ADPKD diagnosis is usually relatively straightforward when enlarged bilateral cystic kidneys are present in combination with a positive family history for ADPKD. In 2009, Pei et al. developed USG criteria for diagnosing ADPKD when the causative gene is unknown, because the original Ravine USG criteria for diagnosing ADPKD appeared to be insufficient [68].

Unlike ADPKD, currently there aren't unified radiological diagnostic criteria for isolated PCLD. Diagnosis is usually made during the fourth to fifth decade of life and is arbitrarily defined as the presence of $>20$ liver cysts as measured by ultrasonography, CT [69], or MRI. The differential diagnosis of PCLD includes simple liver cysts and liver cysts resulting from other systemic diseases such as ADPKD. Qian and his group have proposed recently ultrasonographic diagnostic criteria that can be used to differentiate simple liver cysts from PCLD. In those who have families with autosomal dominant isolated polycystic livers and $<40$ years of age, the presence of any liver cysts is considered to be diagnostic of PCLD. Instead, if they are $>40$ years of age, four or more liver cysts are requested for the diagnosis of PCLD. These criteria, however, need to be further vetted in a larger cohort of PCLD patients [70].

To classify the severity and distribution of cysts in patients with PCLDs, Gigot's classification can be used [32]. It categorizes patients according to the number and size of liver cysts and the amount of remaining liver parenchyma. Patients with $<10$ large $(>10 \mathrm{~cm})$ cysts with remaining large areas of noncystic parenchyma are classified as Gigot type I. Gigot type II includes patients with diffuse involvement of liver parenchyma by multiple medium-sized cysts with large areas of noncystic liver parenchyma remaining. Patients with type III presents large numbers of small and medium-sized liver cysts spread diffusely through the liver parenchyma with only a few area of normal liver parenchyma. The Gigot criteria are useful for crude determination of the severity of PLD, and this classification can help us in planning appropriate therapy.

Treatment

a. Aspiration-sclerotherapy

Aspiration-sclerotherapy is indicated in patients with one or few dominant cyst that are clearly responsible for the complaints. Cysts with a diameter $>5 \mathrm{~cm}$ are usually good candidates for treatment. The procedure requires radiological aspiration and subsequent injection of a sclerosing agent to destruct the cyst wall and prevent recurrence. Puncture of the cyst is performed with a 5 or 7 French catheter with an aspiration needle. Ethanol is the most commonly used agent, but minocycline and tetracycline are alternatives. These latter agents destroy the cyst wall by creating a low $\mathrm{pH}$ within the cyst. The most common complication was abdominal pain caused by peritoneal irritation due to ethanol instillation. The rate of total and partial regression was of $22 \%$ and $19 \%$, respectively [71]. In the majority of patients, symptoms totally disappeared, or a reduction of symptoms occurred.

b. Fenestration

Fenestration involves surgical deroofing and excision of superficial large cysts to achieve a reduction in the volume of the liver and has the advantage that multiple cysts can be treated in one session. The best candidates for this treatment are patients having Gigot type I-II livers repeatedly unresponsive to aspiration-sclerotherapy technique. Two types of approaches have been used: open laparotomy and, more recently, laparoscopy. Laparoscopy has the advantage of less morbidity and reduced hospitalization, but this technique is not the best choice in patients with cysts in cranially located segments, as the VII and the VIII and deep-seated cysts. In this situation, conversion to laparotomy is more likely to be successful.

Common complications of fenestration are ascites, pleural effusion, arterial or venous bleeding, and biliary leakage [72]. Morbidity rate in these patients was in the range of $23 \%$. Mortality was $2 \%$, and the causes of death were irreversible shock, hepatic abscesses, and acute renal failure [71].

c. Segmental hepatic resection

Segmental hepatic resection is indicated in patients with severe Gigot type livers with at least one segment with unaffected liver parenchyma. The procedure is often combined with fenestration of cysts in the remnant segment. Although relief of symptoms is achieved in $86 \%$ of patients, this procedure is associated with considerable morbidity (51\%) and mortality (3\%) [71]. The distortion of the intrahepatic vasculature and biliary tree is a potential source of complications, and the risk of subsequent adhesions might complicate any future liver transplantation. Therefore, we consider this invasive option difficult to pursue in most patients. Resection is considered when fenestration alone is unlikely to significantly reduce liver volume, and when liver transplantation is unwarranted. It is suitable for patients who are significantly incapacitated by their disease and suffer from severe and disabling symptoms due to the massive volume of the polycystic liver.

d. Liver transplantation

Liver transplantation is the only curative option and is indicated in patients with type II/III PCLDs refractory to other treatments, with extremely disabling symptoms, 
seriously reduced quality of life, untreatable complications (for example, portal hypertension), and nutritional compromise [73]. This therapeutic option should be weighed carefully in view of the shortage of available donors, the need for life-long immunosuppression, the fact that PCLDs are not associated with excess liverrelated mortality, and that patients typically present with preserved hepatocellular function even in advanced cases. A combined liver-kidney transplantation should be considered in patients with severe polycystic liver and kidney disease who have end-stage renal disease [74].

e. Transcatheter arterial embolization

Transcatheter arterial embolization (TAE) aims to selectively embolize the hepatic artery branches that supply the major liver cysts, leading to shrinkage of the cyst and diminishing the total liver size. Possible embolizing materials for embolization of the hepatic artery branches are coils, polyvinyl alcohol (PVA) particles, gelatin sponge, and glue. Recently, two small case series of patients treated with TAE showed a reduction of total liver volume and intrahepatic cyst volume by $23.4-26.0 \%$ and $30.7-$ $36.4 \%$, respectively $[75,76]$. However, these studies have limitations due to the small number of patients recruited and the short duration of the follow-up period.

f. Somatostatin analogs

The somatostatin analogs lanreotide and octreotide bind to somatostatin receptors 2,3 , and 5 , which are widely expressed not only in many tissues but also in the epithelia that line cysts. These agents reduce intracellular levels of cAMP by activating signaling cascades through the Gi $\alpha$ subunit, thereby preventing accumulation of fluid in liver cysts. Several studies have reported the substantial positive effects of somatostatin analogs in decreasing liver and kidney growth in ADPKD and PCLD [77-79]. The most common adverse events attributable to somatostatin analog therapy were abdominal cramps and severe steatorrhea. These adverse events disappeared after repeated injections, after administration of pancreatic enzymes, or after reduction of the dose in cases of severe adverse events. Injection granulomas were only reported in patients receiving a somatostatin analog and not in patients on placebo.

Pasireotide is a novel multireceptor synthetic somatostatin analog. In contrast to lanreotide and octreotide, it binds with high affinity to all somatostatin receptors except for somatostatin receptor 4 . This feature suggest that pasireotide is a promising treatment option for reduction of polycystic liver volumes in patients with PCLDs, especially for those who do not respond to octreotide or lanreotide [80].

g. mTOR inhibitors

Another medical option that has gained popularity is the use of mammalian target of rapamycin (mTOR) inhibitors, sirolimus and everolimus. This class of drugs has strong antiproliferative effects [81], and in a retrospective study in ADPKD patients treated with this immunosuppressive regimen after renal transplantation, a significant reduction in polycystic liver volume was observed [82]. Prospective clinical trials of sirolimus and everolimus in ADPKD are currently in progress.

\section{Liver's Macroregenerative Nodules}

Recent research has drawn attention to putative precancerous nodules observed in chronically diseased livers, especially in cirrhosis. These grossly detectable lesions are variably termed "macroregenerative nodule" (MRN), "adenomatoid," or "adenomatous hyperplasia," "dysplastic nodule", and "hepatocellular pseudotumor" and are currently classified into two types, depending on the presence or absence of cytological or architectural atypia. Macroregenerative nodules (MRNs), probably representing a pathway for human hepatocarcinogenesis, are generally classified into type I MRNs (or ordinary adenomatous hyperplasia: nodules without atypia) and type II MRNs (or atypical adenomatous hyperplasia: with atypia) on the basis of imprecise definitions of cytological and architectural atypia. It is currently believed that type II MRNs are probably true precursors of hepatocellular carcinoma, whereas type I lesions may represent large regenerative nodules.

However, many reports have demonstrated that histological examination of type I MRNs is insufficient in many cases to distinguish large regenerative nodules from neoplastic ones; liver cell dysplasia (LCD) of large cell type should not be used as a criterion for terming an MRN; and atypical and expansile "nodule-in-nodule" formation in MRNs should be considered to represent evidence of architectural atypia.

\section{Epidemiology}

It's estimated that the $90 \%$ of HCC start as a micro $(<3-$ $4 \mathrm{~mm}$ ), and then macro (>3-4 mm), regeneration nodule. Macro-nodule's dysplasia is responsible for the malignant change of the nodule until the onset of HCC. So it's very important to detect as soon as possible this type of lesion to stop the course toward HCC $[83,84]$.

In this course, a lot of changes (histology, neoangiogenesis) follow the dysplasia, and all these alterations are responsible of particular signs in US and RNM (or CT) images.

\section{Histology}

The first thing to investigate is the distinction between early HCC and dysplastic nodule [85-92]. 
We can distinguish micronodule, macronodule with a low grade or high grade of dysplasia, and early HCC.

- Micronodule: it is the basic lesion of cirrhosis, it's capsulated, and it has modest size $(4 \mathrm{~mm})$ with the tendency to confluence giving rise to macronodules. The basic structure of hepatocyte is maintained, portal tracts are present, and the system of bile duct is preserved and is represented in its context as the Kupffer cells. The formation of such nodules in cirrhotic liver, however, determines the alteration of lobular architecture due the compression of the surrounding parenchyma and the continuous stimulus proliferative given by the pathogenic agent.

- Macronodules: low-grade (LGDN) is a nodule well distinguished with respect to the surrounding parenchyma, show low cellular atypia, their vascularization is mainly from portal, even if the portion coming from the hepatic artery is increased slightly.

- Macronodules: high-grade (HGDN) is considered the real preneoplastic lesion. Microscopically, they are characterized by small size with more cellular atypia, reduced ratio nucleus/cytoplasm, increased nuclear size, prominent nucleolus, increased mitosis, increased cell density, and fatty degeneration. The unique element of the high grade dysplastic forms is the increase in arterial vascularization due to the presence of so-called unpaired arteries or arterioles not accompanied by bile duct and portal vein resulting in the loss of the structure of the liver lobule. The distinction between high-grade dysplastic nodules and early HCC is based on the occurrence in the latter, on the septal and vascular invasion by neoplastic cells nodular.

- Early HCC: It's a cancerous lesion $<2 \mathrm{~cm}$ with all typical cellular atypia $[92,93]$.

- In cases in which the differential diagnosis is not possible, the lesions should be considered HCCs and treated as such [94].

Many researchers have studied macronodules in explanted cirrhotic livers, performing a detailed description of gross aspects and histological features according to each functional type. In addition, they have been studied the proliferation, apoptosis, and regulatory proteins $\mathrm{P} 53, \mathrm{Bcl}-2, \mathrm{Bcl}-\mathrm{x}$, and Bax in these nodules.

The steady increase in size, as well as in proliferation and apoptotic rates from cirrhosis to HCC, suggests a progression from each diagnostic class to the next. Although most HCCs develop in macronodules harboring livers, some of them do not, suggesting an alternative pathway for hepatocarcinogenesis. The following gross aspects were found useful in selecting the most suspicious nodules: green color, marked color variation inside the nodule, and extracapsular extension were found as indicators of HCC. Steatosis, clear cells, Mallory bodies, and intra-nodular fibrosis could be useful histological criteria to HCC. The deficit of apoptotic rate as compared to proliferation rate from cirrhosis to LGDN could reflect some dysregulation in the cell population control. Different patterns of expression of Bcl-2, Bcl-x, and Bax could play a role in this process. P53 anomalous expression was present only in late stage of cancer development [94].

\section{Diagnostic Algorithm}

Once a lesion is individuated in the liver with US, it's necessary to reach a right diagnosis, especially in patients with cirrhosis.

Usually, this type of lesion measures 3-10 $\mathrm{mm}$. The operator can see a hypoechoic lesion with hyperechoic outline (capsule). These features are not only specific for dysplastic macronodule, but also belong to regenerative nodules. So, CEUS can help the traditional imaging with contrast. Usually, these type of lesion are isoechoic in all vascular phases (portal, artery, vein), but sometimes they could be hypovascular in the arterial phase, or hypervascular, without "washout" during the portal/late phases of CEUS.

The 2nd step of differential diagnosis is represented by CT scan. Today, CT scan is reserved for all lesions visible in US. The evaluation includes scans without contrast medium, with contrast medium, and a dynamic study after the injection of the contrast bolus.

The regenerative nodules are visible on CT in about $25 \%$ of patients and appear as hyperdense nodules. On contrast, in CT scans, these nodules are typically isodense and therefore indistinguishable from remaining liver parenchyma. The dysplastic nodules, instead, generally are slightly hyperdense (compared to the surrounding parenchyma) in basal CT scan, and they have no dye uptake after intravenous contrast resulting hypodense or isodense, especially during late phase. The different vascularization of the lesions, in fact, is the most important feature that can help in differentiating small nodules from HCC.

The 3rd step is magnetic resonance (MR) that is considered the best technique to do differential diagnosis. In the last years, MR had a fast evolution with quick scans that can delete all breath's artifacts. The use of contrast increases the diagnostic power of MR. Today, we have three types of contrast that can be used according to their distribution in liver's parenchyma: (1) extracellular contrast to view lesion's vascularization; (2) hepatospecific contrast captured inside normal hepatocytes, in this way tumoral lesion can be distinguished as not-capturing contrast because of the lack of working hepatocytes in its contest; (3) reticuloendothelial contrast formed by particles of iron oxide and captured inside Kupffer cells that can distinguish a lesion from a normal parenchyma because tumoral lesion do not contain Kupffer cell, and so, they cannot capture this type of contrast. Anyway, MR is also very important in the sequence of impulses used to do the scanning because in this way, it can hide or not a signal from one tissue to another [95-99]. 
Further research, most likely focusing on molecular characteristics of these nodules, may elucidate the true biological nature of MRNs. Such research can identify reliable markers of neoplasia and malignant progression, which will allow a definitive terminology for precancerous hepatocellular lesions to be established. In the meantime, the radiographically determined presence of one or several large nodules in a cirrhotic liver would indicate an increased risk for HCC in that patient, with the malignancy arising either within these nodules or elsewhere. Evidence of MRN found in a biopsy specimen, with or without atypia, should not result in clinical complacency but rather in continued, careful observation [87, 94].

Macroregenerative nodules and dysplastic nodules must alarm the physician during the follow-up of patient with cirrhosis or during an echography made for another reason. It's very important to follow the diagnostic algorithm and to do a biopsy when possible to differentiate early-HCC from benign lesions $[87,94]$.

\section{Mesenchymal Hamartoma of the Liver}

\section{Epidemiology}

Mesenchymal hamartoma of the liver (MHL) is an uncommon hamartomatous growth of mesenchymal tissue, bile ducts, hepatic cords, and blood vessels in the liver. It was described in detail in 1956 by Edmoston. MHL represents $8 \%$ of pediatric hepatic tumors, it's the second most common benign hepatic tumor in childhood [100-102], and it's slightly more frequent in male than female. Most of the cases are diagnosed before the second year of life, with a peak of incident between 15 and 20 months of life. Only 15 cases of hamartomas in adults have been reported in the English language literature worldwide [103-106].

\section{Clinical Presentation}

Symptoms of MHL depend on the patient's age, tumor size, and growth rate.

MHL may be observed prenatally in ultrasonography as a hypoechogenic mass in the liver, and it's often misdiagnosed clinically as a hepatic cyst or as a malignant tumor because of its cystic appearance.

In prenatal period, rapidly growing cystic tumors may lead to decreased fetal albumin production and high risk of hydrops, intestinal obstruction and consequent polyhydramnion, or elevation of the diaphragm and risk of pulmonary hypoplasia. By the displacement of internal organs and compression of the inferior vena cava and umbilical vein, fetus is at risk of premature birth, poor start or congestive heart failure, and intrauterine death. Frequently, placental abnormalities such as thickening, multicystic enlargement of the placenta, or mesenchymal stem villous hyperplasia are associated with MH 1 [107-109].

In older children and adults, the only symptom might be a palpable, asymptomatic, and slow-growth abdominal mass, causing a progressive abdominal distension. Other symptoms, such as nausea and vomiting, respiratory dysfunction, intestinal occlusion, ascites, jaundice, or congestive heart failure, are due to the compression of the tumor mass on surrounding structures and are less common. Sometimes, patients may experiment fever, anorexia and weight loss. Laboratory studies reveal normal or elevated liver enzyme levels as well as AFP and $\beta$-HCG $[110,111]$.

Paradoxically, a few undergo incomplete spontaneous regression and, on rare occasions, others have shown malignant transformation to undifferentiated (embryonal) sarcoma [105].

\section{Pathology}

Most tumors arise in the right lobe of the liver and rarely involved both lobes. It is usually a solid or multicystic solitary nodule, sometimes pedunculated, well demarcated from the adjacent liver tissue but not encapsulated, with variable size from a few centimeters up to $30 \mathrm{~cm}$. These tumors may be often greater than $1 \mathrm{~kg}$ in mass, until to represent over $15 \%$ of child's body mass. Solid areas are gray or pink in color, and cystic spaces might be filled with clear to yellow fluid or gelatinous material [111, 112].

Microscopically, MH consists of branching bile ducts and hepatocytes in single cords or in large groups [113, 114], lying in a myxoid stroma with myofibroblast-like cells, dilated blood vessels and lymphatics, and without atypia or invasion of adjacent liver parenchyma.

Recently, the same cases of MHL in older children or adults have been reported in literature [115], resembling a malignant lesion from a clinical point of view, characterized by unusual histologic features: a prominent myxoid stroma, with a minimal ductular component, and absent cystic spaces. It may be hypothesized that variation in morphology might be related to different evolutive stages of the cell of origin. To support this hypothesis, it has been studied the presence of components of the Notch pathway inside and outside the lesion. Their absence inside the tumor and, in contrast, the expression of Notch2 and HES1 with overrepresented bile ducts might not only explain the lack of bile ducts, but also indicate a more adult phenotype compared with classic pediatric MHL, which show more bile ducts and liver trabeculae embedded in the mesenchymal matrix [105].

Pathogenesis and Molecular Characteristics

The pathogenesis of $\mathrm{MH}$ is not fully explained, and there are some theories that point to developmental abnormalities, 
regional ischemia, or biliary obstruction as a possible cause $[116,117]$.

Cytogenetic analyses describe aberrations involving the chromosomal region $19 \mathrm{q} 13.4$, such as translocations $\mathrm{t}(11 ; 19)$ (q13;q13.4), t(11;19) (q13;q13.3), and t(15;19) (q15;q13.4), as well as interstitial deletion del [18] (q13.1q13,4) and complex rearrangements involving $11 \mathrm{q} 2,17 \mathrm{p} 11$, and $19 \mathrm{q} 13.3$ $[118,119]$.

Despite the benign character of this tumor, it has been supposed that MH might be a precursor lesion to undifferentiated embryonal sarcoma described in the literature arising within MH with similar genetic aberrations $[116,118]$.

\section{Diagnosis}

Diagnosis of $\mathrm{MH}$ is generally based on clinical and imaging studies, followed by bioptic confirmation.

Conventional ultrasound is a well-known, relatively low cost, and noninvasive imaging method which is widely available and easy to perform in consideration of young age of patients. Abdomen computer tomography and magnetic resonance imaging are usually second line examinations used to clarify vascular and surrounding structures in preoperative assessment.

US scan shows a voluminous, well delimited, rounded or oval hepatic mass, with heterogeneous structure due to solid and cystic components. It is composed of variable sizes anechoic cysts, with thin septa inside and thin walls, mixed with solid parts, that appear not much or not at all vascularized in color and power Doppler analysis.

More precise preoperative diagnosis can be based on fine needle aspiration (FNA) cytology to distinguish between hepatoblastoma, hepatocellular carcinoma infantile, hemangioendothelioma, undifferentiated sarcoma, smooth muscle tumors, and inflammatory pseudotumor $[120,121]$.

Hepatoblastoma and infantile hemangioendothelioma concern the same age patients but they are usually solid tumors. Simple cysts are unusual in children and appear as unilocular cysts. It may be hard to differentiate mesenchymal hamartoma from biliary cystadenoma and parasitic cysts, but these hepatic lesions rarely affect pediatric patients.

\section{Treatment and Clinical Outcomes}

$\mathrm{MH}$ is a benign tumor and most of authors recommend complete resection of the tumor as sufficient therapy. After incomplete resection, recurrent benign lesions are possible [2-6]. However, complications after resection such as hemorrhage, cardiac arrest, and pulmonary problems including acute respiratory distress syndrome (ARDS) have been described in the literature with the mortality rate up to $17 \%$ [122].
The mortality rate is $35 \%$ when the tumor is diagnosed in the perinatal period. Cesarean section is preferred when the tumor is large, to avoid the dystocia or traumatic cyst rupture with fatal outcome.

In conclusion, mesenchymal hamartoma is a childhood benign tumor that may reach great dimension, but it has a good prognosis after surgical resection. However, occurrence in the perinatal period is associated with higher mortality due to its rapidly increasing size and fetal growth abnormalities. Diagnosis is based on clinical and imaging studies as well as fine-needle aspiration cytology. MH must be suspected in any infant who presents with a multicystic liver mass. The treatment of choice is surgical resection.

\section{Hepatic Angiomyolipoma}

Hepatic Angiomyolipoma (AML) is a benign mesenchymal neoplasia composed of smooth muscle cells, adipose tissue, and proliferating blood vessels.

AML is a rare tumor discovered occasionally in asymptomatic patients.

It occurs most commonly in the kidney, in which this type of tumor is often associated with tuberous sclerosis.

The liver is the second most common site of AML, though it has been rarely described in other locations such as uterus, retroperitoneum, mediastinum, colon, skin, spleen, and so on $[123,124]$.

AML of the liver was first described in 1976 by Ishak [125].

Since its first description, few hundred of cases have been described in literature.

AML is found in both males and females, but it is most common in adult females $(\mathrm{M}: \mathrm{F}=5: 1)$.

Hepatic AML was once considered a very infrequent lesion, but recently, thanks to early HCC screening programs, it's diagnosed often.

This tumor is composed of varying mixtures of adipose tissue, smooth muscle cells, and thick-walled blood vessels. According to the predominant cell type, this tumor can have a variable histopathology, so, we can describe several types of AML: mixed (the most frequent type, which is composed of all cell types), lipomatous (>70\% of fat), myomatous ( $10 \%$ of fat), and angiomatous $[126,127]$.

According to the fat composition, it's possible to diagnose AML with ultrasounds or computer tomography, but in differential diagnosis must be considered other tumor fat-containing such as hepatic adenomas or hepatocellular carcinomas with fatty metamorphosis and so on. 
Etiology

The etiology of hepatic AML is yet unknown. There are some hypothesis, one of these regards fat cells and smooth muscle cells (SMC), they are both derived from the perivascular epithelioid cells (PECs), for this reason AMLs are allocated to the family of PEC tumors (perivascular epithelioid cell tumor, called also PEComa) [128-130].

The smooth muscle cell component is the most specific for the diagnosis. Indeed, SMC are positive for homatropine methylbromide-45 (HMB45), an antibody that has been discovered on cells of neural crest derivation, like melanocytes and AML's smooth cells [131].

HMB-45 is one of the melanoma markers, expressed only by neoplastic melanocytes.

HMB-45 is becoming a promising marker in the diagnosis of hepatic AML, especially in tumors with a low composition of fat, these types are already not easy diagnosticable only with ultrasounds or tomography [131].

However, for all types of AML, it is impossible to diagnose the type without the histological examination after surgical resection.

\section{Clinic}

Hepatic angiomyolipoma is usually asymptomatic. Tumors are generally discovered incidentally on imaging during a health check-up.

Only a small share of patient complains non-specific to symptoms such as abdominal pain and abdominal fullness discomfort had malaise and mild fever [127, 132].

Acute tumor rupture, although uncommon, has been reported.

\section{Diagnosis}

Generally, the pre-operative diagnosis is very difficult, but ultrasounds, computed tomography (CT), magnetic resonance (MR) imaging, and angiography can identify the fatty component, helping in the differential diagnosis from the hepatocellular carcinoma (HCC).

In general, AML shows the different enhancement pattern from HCC on portal and delayed phases. However, the proportion of fatty tissue in these tumors is variable, and these tumors are known types of AML with minimal fat, these are the most difficult to diagnose because they can mimic HCC [133-136].

AML appears as various patterns in imaging studies, according to the histological composition. Generally, hepatic angiomyolipoma on ultrasound examination appears as a heterogeneously hyperechoic mass, but on ultrasound alone, this lesion may by indistinguishable from hemangioma [137].
Tomography shows a heterogeneously low density mass, while in MRI this tumor has high intensity on T1 and T2 weighted, and lastly on angiography AML appears as a hypervascularity mass.

Generally, magnetic resonance imaging is the most specific study for the detection of fat-components; however, the amount of adipose tissue is variable, often there are tumors with low fat-composition [137].

When it is difficult to make a differential diagnosis between hepatic angiomyolipoma and other fat-containing tumors (fatty metamorphosis of HCC, hepatocellular adenoma with a fat content, lipoma, and liposarcoma), fine needle aspiration (FNAB) may be useful [138].

Thus, the definitive diagnostic study remains the histological examination, by identification of the three different components (smooth muscle cells, adipose tissue, and blood vessels), and particularly throw immunohistochemical analysis, in which SMC are characteristically strongly positive for HMB-45 and Melan-A [127].

HMB-45 is probably the most sensitive immunohistochemical marker for AML, followed by Melan-A [127].

Once the diagnosis is certain, generally, it's recommended a conservative treatment with imaging (watch and wait).

Surgical treatment is suggested in symptomatic patients, or if there are complications, such as a rupture, and finally when a malignant lesion cannot be ruled out with imaging techniques or FNAB [127, 132, 139].

\section{Biliary Cystadenoma}

Epidemiology

Biliary cystadenoma is a rare, benign cystic neoplasm of unknown etiology with slow-growing but with a malignant potential and arising from the biliary ducts; it origin from a primitive hepatobiliary stem cell and it occurs for less than $5 \%$ of hepatobiliary cystic masses; women are predominantly affected in middle-age.

The first description of this neoplasy was in 1943.

The majority of biliary cystadenoma arise from the intrahepatic ducts, predominantly within the left lobe [140]; rarely these lesions are found in the extrahepatic biliary system or gallbladder. The size of tumors varies from 1.5 to $35 \mathrm{~cm}$.

Biliary cystadenoma is often an incidental finding during radiological exam because it's an asymptomatic lesion; the most common symptoms are the presence of palpable mass, non-specific upper abdominal pain, and discomfort, sometimes like biliary calculous pain, gastroduodenal symptoms, or nausea. Other clinical characteristics are recurrent jaundice, weight loss, intolerance to fatty food, and cholangitis. 
The main differential diagnoses are the following: simple hepatic cyst, hydatid cyst, Caroli disease, undifferentiated sarcoma, intraductal papillary mucinous tumor, hepatocellular carcinoma, and biliary cystadenocarcinoma; the hematological tests may help for the correct diagnosis.

Blood test can be abnormal with elevated liver function tests, and occasionally, CA 19.9 and CEA can be elevated too.

\section{Histology}

Biliary cystadenoma is characterized by the presence of cysts with a simple layer of cuboidal or columnar epithelium. There is cellular mesenchymal tissue that looks like ovarian stroma. A marsupial pseudocapsule separates the cystadenoma from the biliary epithelium [141]. There are two types of biliary cystadenoma, mucinous and serous. The more common mucinous type is subdivided by the presence or absence of a mesenchymal stroma between the inner epithelial lining and the outer basement membrane.

Although, both types can undergo malignant transformation to biliary cystadenoma and the absence of a mesenchymal stroma is known to be more aggressive [141].

The epithelium may show varying degrees of dysplasia. High grade dysplasia or invasive carcinoma suggests transformation to cystadenocarcinoma [142].

\section{Diagnosis}

Tumor markers are not helpful but some patient had elevated CA19.9 or CEA.

On radiologic imaging, biliary cystadenoma is multiloculated, multiseptated intrabiliary neoplasm; ultrasound shows cystic nature of the lesion; CT and MRI help to differentiate the nature of fluid within the cyst and show a difference between cystadenocarcinoma.

Preoperative diagnosis may be very difficult; a treatment algorithm involving CEA, CA 19.9, and cyst wall biopsy has been proposed for patient with suspected biliary cystadenoma [143].

\section{Therapy}

Radical excision of the mass is the treatment of choice (hepatectomy or enucleation). Where resection is subtotal, it is recommended a follow-up for the first 2 years [144] instead the prognosis after a fully resection is excellent because recurrence is uncommon.

In conclusion, biliary cystadenoma is an uncommon cystic benign tumor. Its diagnosis should be considered in cystic lesion of the liver in middle-age woman. The best treatment is total resection to avoid malignant transformation.

\section{Nodular Regenerative Hyperplasia}

Nodular regenerative hyperplasia (NRH) is a benign proliferative process in which normal hepatic parenchyma is replaced by diffuse regenerative nodules of hepatocytes with minimal associated fibrosis. A classification system proposed by Wanless in 1990 [145] provided histological criteria for the diagnosis of NRH. These included the presence of hepatocellular nodules less than $3 \mathrm{~mm}$ in diameter that were not surrounded by fibrosis (nodules graded $0-3$ based on the extent of nodularity noted through all fields of the biopsy), and the presence of fibrous septa (graded 0-3). Biopsy specimens that met the criteria of 3 nodularity and $0-1$ fibrous septa were classified as nodular regenerative hyperplasia.

The prevalence of NRH per autopsy studies is approximately $2 \%$ [146]. There is no gender predilection, and although NRH mainly affects patients older than 60 , cases have been reported in children as well. The nodules vary in size from $1 \mathrm{~mm}$ to $1 \mathrm{~cm}$. NRH is associated with lymphoproliferative disorders (through thrombophilia secondary to malignancy, direct invasion of tumor, or chemotherapy), rheumatoid arthritis, primary biliary cirrhosis, bone marrow transplantation, hereditary hemorrhagic telangiectasia, polyarteritis nodosa, Budd-Chiari syndrome, liver transplantation (possibly secondary to postoperative hepatic vascular alterations or the use of azathioprine), amyloidosis, Felty syndrome, and HCC.

Most patients with NRH are asymptomatic; however, patients may present with stigmata of portal hypertension. Most patients with NRH have normal hepatic biochemical tests, although $10 \%$ to $25 \%$ of patients may have mild elevations, particularly in alkaline phosphatise [147]. Hepatic synthetic function is usually preserved, and fulminant liver failure is rare.

On gross examination of the liver, the normally homogenous hepatic parenchyma shows a diffuse transformation into nodules of $1-3 \mathrm{~mm}$ in size. Unlike cirrhosis, there is no fibrosis separating nodules - each nodule presses directly against its neighbor. Although nodules greater than $15 \mathrm{~mm}$ have been described, these are frequently revealed to be composed of smaller nodules when examined microscopically $[145,148]$. The hepatocytes within the nodule are arranged in plates that are more than 1 cell thick. These cells may be enlarged and have hypertrophic nuclei. Between individual nodules, the hepatocytes are small and atrophic and are pressed together into thin, parallel plates.

It has been suggested that the nodular transformation in $\mathrm{NRH}$ of the liver is a consequence of alterations in blood flow. Morphologically, abnormalities of portal and/or central veins are frequently observed, and many drugs that are associated with NRH also cause other types of vascular injury.

Drugs have also been associated with the development of NRH. Azathioprine, a purine analog, is the most commonly associated drug, as noted in case reports of patients receiving 
Table 1 Classification of hepatic tumors [156]

\begin{tabular}{ll}
\hline Benign & Malignant \\
\hline Hepatic adenoma & Hepatocellular carcinoma \\
Regenerative nodules & Fibrolamellar carcinoma \\
Nodular regenerative hyperplasia & Hepatoblastoma \\
Focal nodular hyperplasia & Cholangiocarcinoma \\
Bile duct adenoma & Cystadenocarcinoma \\
Biliary cystadenoma & Angiosarcoma \\
Hemangioma & Primary lymphoma \\
Angiolipoma & Metastases \\
\hline
\end{tabular}

this drug for immunosuppression after liver transplantation [149].

The association of NRH with systemic diseases has been previously discussed. Many of these diseases involve a vasculitic process including polyarteritis nodosa and rheumatoid arthritis. Morphometric studies of these cases suggest that acute and chronic inflammation of intrahepatic arteries leads to secondary portal venous obliteration and thrombosis of the adjacent portal veins, which may result in NRH [148, 150, $151]$.

A few studies have also described an association between the early (stage I or II) histological stages of primary biliary cirrhosis and nodular regenerative hyperplasia $[152,153]$. The largest of these studies evaluated the liver biopsies of 64 patients with early primary biliary cirrhosis and found that $43 \%$ of these biopsies had some degree of nodular transformation without fibrosis. Approximately $54 \%$ of the liver biopsies with NRH had evidence for a vascular lesion (decreased portal vein luminal diameter due to intimal fibrosis or thrombotic occlusion [152]). The authors also reported an increased incidence of portal hypertension with splenomegaly and one patient with esophageal varices in this subset of patients with NRH and early primary biliary cirrhosis. In this situation, it was possible that the nodular transformation was contributing to portal hypertension. NRH progresses slowly, and the prognosis reflects the development and progression of portal hypertension. Patients with portal hypertension associated with NRH have a 5-year survival of $90 \%$ and 30 year survival of $55 \%$ [154]. NRH is not thought to be a premalignant condition, and the association between HCC and $\mathrm{NRH}$ is unclear.

The diagnosis of nodular regenerative hyperplasia is made by liver biopsy - either needle biopsy or open wedge biopsy. This must be performed in the appropriate clinical setting, usually, as an evaluation of unexplained portal hypertension, not associated with cirrhosis.

Sensitive imaging modalities such as contrast-enhanced computed tomography and magnetic resonance imaging can help characterize various nodular liver lesions; however, histological evaluation is the only way to make a definitive diagnosis of NRH and rule out conditions such as hepatocellular carcinoma and cirrhosis. In the case of needle biopsy, the gauge of the needle is an important consideration. Regenerative nodules may be missed if the needle is too narrow, as is often the case with transjugular liver biopsy, thus making the diagnosis of NRH difficult.

It is important to note that more than one type of nodular lesion can coexist in the same liver; for example, NRH and hepatic adenoma may both be present in the same patient. This is an important distinction clinically, because portal hypertension may result from NRH, whereas disabling pain or hemorrhage may be due to hepatic adenoma, and different treatment options would be offered for each situation. Histologically, patients with portal hypertension not associated with cirrhosis may present with NRH, hepatoportal sclerosis (portal venopathy), central venous obliteration, sinusoidal dilation, or some combination of these lesions [155].

Treatment of NRH is directed at treating the underlying medical condition and preventing complications of portal hypertension.

Nodular regenerative hyperplasia is believed to be a hyperproliferative response to an obstructive portal venopathy and the resulting uneven perfusion of the hepatic parenchyma. NRH should be included in the differential diagnosis of patients who present with unexplained portal hypertension. The hepatologist should have a high index of suspicion in patients with systemic diseases known to be associated with NRH or in patients who have had an exposure to drugs that have been associated with NRH. Liver biopsy is essential for diagnosis, and at present, the mainstay of treatment is management of the underlying disorder and control of portal hypertension. Understanding the pathophysiology of $\mathrm{NRH}$ might elucidate understanding of regenerative nodules in cirrhosis. As understanding of NRH and the mechanisms underlying it are developed, novel treatment strategies are likely to emerge for NRH and possibly other liver diseases as well (Table 1) [156].

\section{Conclusions}

Hepatocellular carcinoma (HCC) is one of the most common malignant tumors in some areas of the world; there is an increasing incidence worldwide. Approximately 750,000 new cases are reported per year [157-159]. More than $75 \%$ of cases occur in the Asia-Pacific region, largely in association with chronic hepatitis B virus (HBV) infection [160-162]. The incidence of HCC is increasing in the United States and Europe because of the increased incidence of hepatitis $\mathrm{C}$ virus (HCV) infection [163, 164]. Unlike the liver HCC, benign tumors are less frequent. However, they represent a chapter always more interesting of liver disease; in fact a careful differential diagnosis with the forms of malignant tumor is often required in such a way so as to direct the patient to the correct therapy [156]. 
Disclosures The authors state no conflicts of interest.

\section{References}

1. Cowles RA, Mulholland MW. Solitary hepatic cysts. J Am Coll Surg. 2000;191:311-21.

2. Del Poggio P, Buonocore M. Cystic tumors of the liver: a practical approach. World J Gastroenterol. 2008;14:3616-20.

3. Martin IJ, McKinley AJ, Currie EJ, et al. Tailoring the management of nonparasitic liver cysts. Ann Surg. 1998;228:167-72.

4. Carrim ZI, Murchison JT. The prevalence of simple renal and hepatic cysts detected by spiral computed tomography. Clin Radiol. 2003;58:626-9.

5. Karavias DD, Tsamandas AC, Payatakes AH, et al. Simple (nonparasitic) liver cysts: clinical presentation and outcome. Hepatogastroenterology. 2000;47:1439-43.

6. Eliason EL, Smith DC. Solitary nonparasitic cyst of the liver: case report. Clinics. 1944;3:607.

7. Sanfelippo PM, Beahrs OH, Weiland LH. Cystic disease of the liver. Ann Surg. 1974;179:922-5.

8. Feldman M. Polycystic disease of the liver. Am J Gastroenterol. 1958;28:83-6.

9. Cellier C, Cuenod CA, Deslandes P, Auroux J, Landi B, Siauve N, et al. Symptomatic hepatic cysts: treatment with single shot injection of minocycline hydrochloride. Radiology. 1998;206:205-9.

10. Gaines PA, Sampson MA. The prevalence and characterization of simple hepatic cysts by ultrasound examination. Br J Radiol. 1989;62:335-7.

11. Sanchez H, Gagner M, Rossi RL, Jenkins RL, Lewis WD, Munson JL, et al. Surgical management of non-parasitic cystic disease of the liver. Am J Surg. 1991;161:113.

12. Caremani M, Vincenti A, Benci A, et al. Ecographic epidemiology of non-parasitic hepatic cysts. J Clin Ultrasound. 1993;21:115-8.

13. Bahirwani R, Reddy KR. Review article: the evaluation of solitary liver masses. Aliment Pharmacol Ther. 2008;28:953-65. doi:10. 1111/j.1365-2036.2008.03805.x].

14. Klinger PJ, Gadenstatter M, Schmid T, Bodner E, Schwelberger HG. Treatment of hepatic cysts in the era of laparoscopic surgery. $\mathrm{Br}$ J Surg. 1997;84:438-44.

15. Waanders E, van Keimpema L, Brouwer JT, van Oijen MG, Aerts $\mathrm{R}$, Sweep FC, et al. Carbohydrate antigen WJG|www.wjgnet.com 3551 June 21, 2013|volume 19:23. Liver Int. 2009;29:1389-95.

16. Bertino G, Ardiri AM, Boemi P, Bruno CM, Valenti M, Mazzarino MC, et al. Meaning of elevated CA 19-9 serum levels in chronic hepatitis and HCV-related cirrhosis. Minerva Gastroenterol Dietol. 2007;53(4):305-9.

17. Bertino G, Ardiri AM, Calvagno GS, Boemi PM. In chronic viral hepatitis without malignancy, abnormal serum carbohydrate 19-9 antigen levels are associated with liver disease severity and are related to different viral aetiology. Dig Liver Dis. 2010;42(6):458-9.

18. Bertino G, Ardiri AM, Calvagno GS, Malaguarnera G, Interlandi D, Vacante M, Bertino N, Lucca F, Madeddu R, Motta M. Carbohydrate 19.9 Antigen Serum Levels in Liver Disease. BioMed Research International 2013;(531640):1-6. doi:10.1155/ 2013/531640

19. Choi HK, Lee JK, Lee KH, Lee KT, Rhee JC, Kim KH, et al. Differential diagnosis for intrahepatic biliary cystadenoma and hepatic simple cyst: significance of cystic fluid analysis and radiologic findings. J Clin Gastroenterol. 2010;44:289-93.

20. Seo JK, Kim SH, Lee SH, Park JK, Woo SM, Jeong JB, et al. Appropriate diagnosis of biliary cystic tumors: comparison with atypical hepatic simple cysts. Eur J Gastroenterol Hepatol. 2010;22:989-96.
21. Spiegel RM, King DL, Green WM. Ultrasonography of primary cysts of the liver. AJR Am J Roentgenol. 1978;131:235-8.

22. Taylor KJ, Richman TS. Diseases of the liver. Semin Roentgenol. 1983;18:94-101.

23. Vachha B, Sun MR, Siewert B, Eisenberg RL. Cystic lesions of the liver. AJR Am J Roentgenol. 2011;196:W355-66. doi:10.2214/ AJR.10.5292. PMID: 21427297.

24. Albiin N. MRI of focal liver lesions. Curr Med Imaging Rev. 2012;8:107-16.

25. Gigot JF, Legrand M, Hubens G, de Lanniere L, Wibin E, Deweer F, et al. Laparoscopic treatment of non parasitic liver cysts: adequate selection of patients and surgical technique. World J Surg. 1996;20: 556-61.

26. Shamshi K, Deckers F, De Schepper A. Unusual cystic disease liver lesions: a pictorial essay. Eur J Radiol. 1993;16:79-84.

27. Saini S, Mueller PR, Ferucci Jr JT, Simeone JF, Wittenberg J, Butch RJ. Percutaneous aspiration of hepatic cysts does not provide definite therapy. Am J Roentgenol. 1983;141:559-60.

28. Doty JE, Tompkins RK. Management of cystic disease of the liver. Surg Clin North Am. 1989;69:285-95.

29. Kairaluoma NU, Leinonen A, Stahlberg M, Paivansalo M, Kiviniemi H, Siniluoto T. Percutaneous aspiration and alcohol sclerotherapy for symptomatic hepatic cysts. An alternative to surgical intervention. Ann Surg. 1989;210:208-15.

30. Van Sonnenberg E, Wroblicka JT, D'Agostino HB, Mathieson JR, Casola G, O'Laoida R. Symptomatic hepatic cysts: percutaneous drainage and sclerosis. Radiology. 1994;190:387-92.

31. Bean WJ, Rodan BA. Hepatic cysts: treatment with alcohol. Am J Roentgenol. 1985;144:237-41.

32. Yamada N, Shinwaza H, Ukai K, Makino N, Matsuhashi T, Wakabayashi H, et al. Treatment of symptomatic cysts by percutaneous instillation of minocycline hydrochloride. Dig Dis Sci. 1994;39:2503-9.

33. Litwin DEM, Taylor BR, Langer B, Greig P. Nonparasitic cysts of the liver. The case for conservative surgical management. Ann Surg. 1987;205:45-8.

34. Edwards JD, Eckhauser FE, Knol JA, Strodel WE, Appelman HD. Optimizing surgical management of symptomatic solitary hepatic cysts. Am Surg. 1987;53:510-4.

35. Diez J, Decoud J, Gutierrez L, Suhl A, Merello J. Laparoscopic treatment of symptomatic cysts of the liver. Br J Surg. 1998;85:25-7.

36. Lai ECS, Wong J. Symptomatic non parasitic cysts of the liver. World J Surg. 1990;14:452-6.

37. Everson GT, Helmke SM, Doctor B. Advances in management of polycystic liver disease. Expert Rev Gastroenterol Hepatol. 2008;2: 563-76.

38. Polycystic liver diseases: Congenital disorders of cholangiocyte signaling. Gastroenterology 2011;140:1855-1859.

39. Drenth JPH, Chrispijn M, Bergmann C. Congenital fibrocystic liver diseases. Best Practice Res Clin Gastroenterol. 2010;24:573-84.

40. Desmet VJ. Congenital diseases of intrahepatic bile ducts: variations on the theme "ductal plate malformation". Hepatology. 1992;16: 1069-83.

41. Todani T, Watanabe Y, Narusue M, Tabuchi K, Okajima K. Congenital bile duct cysts: classification, operative procedures, and review of thirty-seven cases including cancer arising from choledochal cyst. Am J Surg. 1977;134:263-9.

42. Sessa A, Meroni M, Righetti M, et al. Autosomal recessive polycystic kidney disease. Contrib Nephrol 2001:50-6.

43. Gunay-Aygun M, et al. PKHD1 sequence variations in 78 children and adults with autosomal recessive polycystic kidney disease and congenital hepatic fibrosis. Mol Genet Metab. 99(2):160-73.

44. Masyuk AI, Masyuk TV, LaRusso NF. Cholangiocyte primary cilia in liver health and disease. Dev Dyn. 2008;237: 2007-12. 
45. Wheatley DN. Primary cilia in normal and pathological tissues. Pathobiology. 1995;63:222-38.

46. Davenport JR, Yoder BK. An incredible decade for the primary cilium: a look at a once-forgotten organelle. Am J Physiol Renal Physiol. 2005;289:F1159-69.

47. Onorib P, Franchittoa A, Mancinellia R, Carpinoe G, Alvarof D, Francisc H, et al. Polycystic liver diseases. Dig Liver Dis. 2010;42: 261-71.

48. Harris PC, Torres VE. Polycystic kidney disease. Annu Rev Med. 2009;60:321-37.

49. Lal M, Song X, Pluznick JL, et al. Polycystin-1C-terminal tail associates with beta-catenin and inhibits canonical Wnt signaling. Hum Mol Genet. 2008;17:3105-17.

50. Anyatonwu GI, Estrada M, Tian X, et al. Regulation of ryanodine receptor-dependent calcium signaling by polycystin-2. Proc Natl Acad Sci U S A. 2007;104:6454-9.

51. Geng L, Boehmerle W, Maeda Y, et al. Syntaxin 5 regulates the endoplasmic reticulum channel-release properties of polycystin-2. Proc Natl Acad Sci U S A. 2008;105:15920-5.

52. Torrice A, Cardinale V, Gatto M, et al. Polycystins play a key role in the modulation of cholangiocyte proliferation. Dig Liver Dis. 2010;42(5):377-85.

53. Parker E, Newby LJ, Sharpe CC, et al. Hyperproliferation of PKD1 cystic cells is induced by insulin-like growth factor-1 activation of the Ras/Raf signaling system. Kidney Int. 2007;72:157-65.

54. Grantham JJ, Ye M, Gattone VH. In vitro fluid secretion by epithelium from polycystic kidneys. J Clin Invest. 1995;95:195-202.

55. Qian F, Watnick TJ, Onuchic LF, et al. The molecular basis of focal cyst formation in human autosomal dominant polycystic kidney disease type I. Cell. 1996;87:979-87.

56. Davila S, Furu L, Gharavi AG, et al. Mutations in SEC63 cause autosomal dominant polycystic liver disease. Nat Genet. 2004;36: $575-7$.

57. Drenth JP, te Morsche RH, Smink R, et al. Germline mutations in PRKCSH are associated with autosomal dominant polycystic liver disease. Nat Genet. 2003;33:345-7.

58. Mai W, Chen D, Ding T, et al. Inhibition of Pkhd1 impairs tubulomorphogenesis of cultured IMCD cells. Mol Biol Cell. 2005;16:4398-409.

59. Van Keimpema L, De Koning DB, Van Hoek B, Van Den Berg AP, Van Oijen MG, De Man RA, et al. Patients with isolated polycystic liver disease referred to liver centres: clinical characterization of 137 cases. Liver Int. 2011;31(1):92-8.

60. Hoevenaren IA, Wester R, Schrier RW, McFann K, Doctor RB, Drenth JP, et al. Polycystic liver: clinical characteristics of patients with isolated polycystic liver disease compared with patients with polycystic liver and autosomal dominant polycystic kidney disease. Liver Int. 2008;28(2):264-70.

61. Shrestha R, Mckinley C, Russ P, Scheninger A, Bonner T, Showalter R, et al. Postmenopausal estrogen therapy selectively stimulates hepatic enlargement in women with autosomal dominant polycystic kidney disease. Hepatol. 1997;26(5): 1282-6.

62. Alvaro DMancino MG, Onori P, Franchitto A, Alpini G, Francis H, Glaser S, et al. Estrogens and the pathophysiology of the biliary tree. World J Gastroenterol. 2006;12(22):3537-45.

63. Abascal J, Moya M, Martin F. Infection of hepatic cysts in polycystic disease. World J Surg. 1984;8(3):424-5.

64. Dmitrewski J. Obstructive jaundice associated with polycystic liver. Disease HPB Surg. 1996;10(2):117-20.

65. Qian Q, Li A, King BF, Kamath PS, Lager DJ, Huston 3rd J, et al. Clinical profile of autosomal dominant polycystic liver disease. Hepatology. 2003;37(1):164-71.

66. Schievink WI, Spetzler RF. Screening for intracranial aneurysms in patients with isolated polycystic liver disease. J Neurosurg. 1998;89(5):719-21.
67. Waanders E, van Keimpema L, Brouwer JT, van Oijen MG, Aerts R, Sweep FC, et al. Carbohydrate antigen 19-9 is extremely elevated in polycystic liver disease. Liver Int. 2009;29(9):1389-95.

68. Pei Y, Obaji J, Dupuis A, Paterson AD, Magistroni R, Dicks E, et al. Unified criteria for ultrasonographic diagnosis of ADPKD. J Am Soc Nephrol. 2009;20(1):205-12.

69. Levine E, Cook LT, Grantham JJ. Liver cysts in autosomaldominant polycystic kidney disease: clinical and computed tomographic study. AJR Am J Roentgenol. 1985;145(2):229-33.

70. Qian Q et al. Isolated polycystic liver disease. Chronic Kidney Dis. 2010;17(2):181-9.

71. Drenth JP, Chrispijn M, Nagorney DM, Kamath PS, Torres VE. Medical and surgical treatment options for polycystic liver disease. Hepatology. 2010;52(6):2223-30.

72. Van Keimpema L, Drenth JP. Polycystic liver disease: a critical appraisal of hepatic resection, cyst fenestration, and liver transplantation. Ann Surg. 2011;253:419.

73. Russell RT, Pinson CW. Surgical management of polycystic liver disease. World J Gastroenterol. 2007;13(38):5052-9.

74. Chui AK, Koorey D, Pathania OP, Rao AR, McCaughan GW, Sheil AG. Polycystic disease: a rare indication for combined liver and kidney transplantation. Hong Kong Med J. 2000;6(1): $116-8$.

75. Takei R, Ubara Y, Hoshino J, et al. Percutaneous transcatheter hepatic artery embolization for liver cysts in autosomal dominant polycystic kidney disease. Am J Kidney Dis. 2007;49:744-52.

76. Wang MQ, Duan F, Liu FY, Wang ZJ, Song P. Treatment of symptomatic polycystic liver disease: transcatheter super-selective hepatic arterial embolization using a mixture of NBCA and iodized oil. Abdom Imaging. 2013;38(3):465-73.

77. Hogan MC, Masyuk TV, Page L, Holmes 3rd DR, Li X, Bergstralh EJ, et al. Somatostatin analog therapy for severe polycystic liver disease: results after 2 years. Nephrol Dial Transplant. 2012;27(9): 3532-9.

78. Temmerman F, Gevers T, Ho TA, Vanslembrouck R, Coudyzer W, van Pelt J, et al. Safety and efficacy of different lanreotide doses in the treatment of polycystic liver disease: pooled analysis of individual patient data. Aliment Pharmacol Ther. 2013;38(4):397-406.

79. Gevers TJ, Inthout J, Caroli A, Ruggenenti P, Hogan MC, Torres VE, et al. Young women with polycystic liver disease respond best to somatostatin analogues: a pooled analysis of individual patient data. Gastroenterology. 2013;145(2):357-65. e1-2.

80. Masyuk TV, Radtke BN, Stroope AJ, Banales JM, Gradilone SA, Huang B, et al. Pasireotide is more effective than octreotide in reducing hepatorenal cystogenesis in rodents with polycystic kidney and liver diseases. Hepatology. 2013;58(1):409-21.

81. Walz G. Therapeutic approaches in autosomal dominant polycystic kidney disease (ADPKD): is there light at the end of the tunnel? Nephrol Dial Transplant. 2006;21(7):1752-7.

82. Shillingford JM, Murcia NS, Larson CH, et al. The mTOR pathway is regulated by polycystin-1, and its inhibition reverses renal cystogenesis in polycystic kidney disease. Proc Natl Acad Sci U S A. 2006;103(14):5466-71.

83. Kudo M, Izumi N, Kokudo N, Matsui O, Sakamoto M, Nakashima O, et al. HCC Expert Panel of Japan Society of Hepatology. Management of hepatocellular carcinoma in Japan: ConsensusBased Clinical Practice Guidelines proposed by the Japan Society of Hepatology (JSH) 2010 updated version. Dig Dis. 2011;29(3): 339-64.

84. Bruix J, Sherman M. American Association for the Study of Liver Diseases. Management of hepatocellular carcinoma: an update. Hepatology. 2011;53(3):1020-2.

85. Biondi A, Malaguarnera G, Vacante M, Berretta M, D'Agata V, Malaguarnera M, et al. Elevated serum levels of chromogranin A in hepatocellular carcinoma. BMC Surg. 2012;12(1):S7. 
86. Malaguarnera G, Paladina I, Giordano M, Malaguarnera M, Bertino G, Berretta M. Serum markers of intrahepatic cholangiocarcinoma. Dis Markers. 2013;34(4):219-28.

87. Bertino G, Ardiri A, Malaguarnera M, Malaguarnera G, Bertino N, Calvagno GS. Hepatocellular carcinoma serum markers. Semin Oncol. 2012;39(4):410-33.

88. Bertino G, Neri S, Bruno CM, Ardiri AM, Calvagno GS, Malaguarnera $\mathrm{M}$, et al. Diagnostic and prognostic value of alphafetoprotein, des- $\gamma$-carboxy prothrombin and squamous cell carcinoma antigen immunoglobulin $\mathrm{M}$ complexes in hepatocellular carcinoma. Minerva Med. 2011;102(5):363-71. Review.

89. Di Carlo I, Mannino M, Toro A, Ardiri A, Galia A, Cappello G, et al. Persistent increase in alpha-fetoprotein level in a patient without underlying liver disease who underwent curative resection of hepatocellular carcinoma. A case report and review of the literature. World J Surg Oncol. 2012;10:79. Review.

90. Bertino G, Ardiri AM, Santonocito MM, Boemi PM. Some patients with HCC haven't abnornormal des-gamma-carboxy prothrombin and alpha-fetoprotein levels. Panminerva Med. 2009;51(2):133-4.

91. Bertino G, Ardiri AM, Calvagno GS, Bertino N, Boemi PM. Prognostic and diagnostic value of des-gamma-carboxy prothrombin in liver cancer. Drug News Perspect. 2010;23(8):498-508. Review.

92. Borzio M, Fargion S, Borzio F, et al. Impact of large regenerative, low grade and high grade dysplastic nodules in hepatocellular carcinoma development. J Hepatol. 2003;39:208-14.

93. Jang HJ, Kim TK, Wilson SR. Small nodules $(1-2 \mathrm{~cm})$ in liver cirrhosis: characterization with contrast-enhanced ultrasound. Eur J Radiol. 2009;72:418-24.

94. Bertino G, Di Carlo I, Ardiri A, Calvagno GS, Demma S, Malaguarnera G, et al. Systemic therapies in hepatocellular carcinoma: present and future. Future Oncol. 2013;9(10): $1533-48$.

95. Anis M, Irshad A. Imaging of hepatocellular carcinoma: practical guide to differential diagnosis. Clin Liver Dis. 2011;15(2):335-52.

96. Lencioni R, Piscaglia F, Bolondi L. Contrast-enhanced ultrasound in the diagnosis of hepatocellular carcinoma. J Hepatol. 2008;48(5): 848-57.

97. Kudo M. Multistep human hepatocarcinogenesis: correlation of imaging with pathology. J Gastroenterol. 2009;44 Suppl 19:112-8.

98. Dai Y, Chen MH, Fan ZH, Yan K, Yin SS, Zhang XP. Diagnosis of small hepatic nodules detected by surveillance ultrasound in patients with cirrhosis: comparison between contrast-enhanced ultrasound and contrast-enhanced helical computed tomography. Hepatol Res. 2008;38:281-90.

99. Giorgio A, Ferraioli G, Tarantino L, et al. Contrast-enhanced sonographic appearance of hepatocellular carcinoma in patients with cirrhosis: comparison with contrastenhanced helical CT appearance. AJR Am J Roentgenol. 2004;183:1319-26.

100. Rosado E, Cabral P, Campo M, Tavares A. Mesenchymal hamartoma of the liver - a case report and literature review. J Radiol Case Rep. 2013;7:35-43.

101. Martínez-Mier G, Cañas-Acar J, Gómez-Dorantes S, SantosAguilar U, Alderete-Vázquez G, Franco-Ahumada GE. Left lobe mesenchymal hamartoma of liver. Uncommon location. Cir Cir. 2012;80:466-9.

102. Chandramouleeswari K, Anita S, Shivali B. Mesenchymal hamartoma of the liver: a case report. J Clin Diagn Res. 2012;6:1552-4.

103. Siddiqui MA, McKenna BJ. Hepatic mesenchymal hamartoma: a short review. Arch Pathol Lab Med. 2006;130:1567-9.

104. Stringer MD, Alizai NK. Mesenchymal hamartoma of the liver: a systematic review. J Pediatr Surg. 2005;40(11):1681-90.

105. Mori R, Morioka D, Morioka K, et al. Giant mesenchymal hamartoma of the liver in an adult. J Hepatobiliary Pancreat Surg. 2008;15:667-9.
106. Laberge JM, Patenaude Y, Desilets V, et al. Large hepatic mesenchymal hamartoma leading to mid-trimester fetal demise. Fetal Diagn Ther. 2005;20:141-5.

107. Cornette J, Festen S, van den Hoonaard TL, Steegers EA. Mesenchymal hamartoma of the liver: a benign tumor with deceptive prognosis in the perinatal period. Case report and review of the literature. Fetal Diagn Ther. 2009;25:196-202.

108. Bessho T, Kubota K, Komori S, et al. Prenatally detected hepatic hamartoma: another cause of non-immune hydrops. Prenat Diagn. 1996;16:337-41.

109. Mittermayer C, Bettelheim D, Horcher E, et al. Prenatal sonographic detection of a giant multiseptate hepatic cyst in the third trimester. Ultrasound Obstet Gynecol. 2002;20:97-8.

110. Mack-Detlefsen B, Boemers TM, Groneck P, Bald R. Multiple hepatic mesenchymal hamartomas in a premature associated with placental mesenchymal dysplasia. J Pediatr Surg. 2011;46: e23-5.

111. Abdulkader I, Fraga M, Pérez-Becerra E, et al. Mesenchymal hamartoma of the liver; clinicopathological, immunohistochemical and flow cytometric study of two cases. Hepatol Res. 2004;28:216-9.

112. Millard J, Fraser N, Stewart RJ. Mesenchymal hamartoma of the liver: is biopsy always necessary? Pediatr Surg Int. 2006;22:622-5.

113. Cook JR, Pfeifer JD, Dehner LP. Mesenchymal hamartoma of the liver in the adult: association with distinct clinical features and histological changes. Hum Pathol. 2002;33:893-8.

114. Virgone C, Cecchetto G, Dall'igna P, Zanon GF, Cillo U, Alaggio R. Mesenchymal hamartoma of the liver in older children: an adult variant or a different entity? Report of a case with review of the literature. Appl Immunohistochem Mol Morphol. 2012.

115. Rajaram V, Knezevich S, Bove KE, et al. DNA sequence of the translocation breakpoints in undifferentiated embryonal sarcoma arising in mesenchymal hamartoma of the liver harboring the $\mathrm{t}(11 ; 19)(\mathrm{q} 11 ; \mathrm{q} 13.4)$ translocation. Genes Chromosomes Cancer. 2007;46:508-13.

116. Otal TM, Hendricks JB, Pharis P, Donnelly WH. Mesenchymal hamartoma of the liver. DNA flow cytometric analysis of eight cases. Cancer. 1994;74:1237-42.

117. O’Sullivan MJ, Swanson PE, Knoll J, et al. Undifferentiated embryonal sarcoma with unusual features arising within mesenchymal hamartoma of the liver: report of a case and review of the literature. Pediatr Dev Pathol. 2001;4:482-9.

118. Murthi GV, Paterson L, Azmy A. Chromosomal translocation in mesenchymal hamartoma of liver: what is its significance? J Pediatr Surg. 2003;38:1543-5.

119. Talmon GA, Cohen SM. Mesenchymal hamartoma of the liver with an interstitial deletion involving chromosome band 19q13.4: a theory as to pathogenesis? Arch Pathol Lab Med. 2006; $130: 1216-8$.

120. Jiménez-Heffernan JA, Vicandi B, López-Ferrer P, et al. Fine-needle aspiration cytology of mesenchymal hamartoma of the liver. Diagn Cytopathol. 2000;22:250-3.

121. Malhotra V, Gondal R, Tatke M, Sarin SK. Fine needle aspiration cytologic appearance of inflammatory pseudotumor of the liver. A case report Acta Cytol. 1997;41(4 Suppl):1325-8.

122. Fuchs J, Schweinitz DV, Feickert HJ. Acute respiratory distress syndrome following resection of a mesenchymal hamartoma of the liver. Med Pediatr Oncol. 1999;32:151-3.

123. Insabato L, De Rosa G, Terraciano LM, Fazioli F, Di Santo F, Rosai J. Primary monotypic epithelioid angiomyolipoma of bone. Histopathology. 2002;40:286-90.

124. Dalle I, Sciot R, de Vos R, Aerts R, van Damme B, Desmet V, et al. Malignant angiomyolipoma of the liver: a hitherto unreported variant. Histopathology. 2000;36:443-50.

125. Ishak KG. Mesenchymal tumors of the liver. In: Okuda K, Peters RL, editors. Hepatocellular carcinoma. New York: John Wiley Medical; 1976. p. 247-304. 
126. Banshodani M, Ishiyama K, Amano H, Tashiro H, Arihiro K, Itamoto $\mathrm{T}$, et al. Hepatic angiomyolipoma with minimal intratumoral fat content. Case Rep Gastroenterol. 2009;3:324-31.

127. Tsui WM, Colombari R, Portmann BC, Bonetti F, Thung SN, Ferrell LD, et al. Hepatic angiomyolipoma: a clinicopathologic study of 30 cases and delineation of unusual morphologic variants. Am J Surg Pathol. 1999;23:34-48.

128. Bonetti F, Pea M, Martignoni G, et al. Clear cell ("sugar") tumor of the lung is a lesion strictly related to angiomyolipoma-the concept of a family of lesions characterized by the presence of the perivascular epithelioid cells (PEC). Pathology. 1994;26: 230-6.

129. Fadare O, Parkash V, Yilmaz Y, et al. Perivascular epithelioid cell tumor (PEComa) of the uterine cervix associated with intraabdominal "PEComatosis": a clinicopathological study with comparative genomic hybridization analysis. World J Surg Oncol. 2004;2:35-46.

130. Bonetti F, Pea M, Martignoni G, Zamboni G, Manfrin E, Colombari $\mathrm{R}$, et al. The perivascular epithelioid cell and related lesions. Adv Anat Pathol. 1997;4:343-58.

131. Makhlouf HR, Ishak KG, Shekar R, Sesterhenn IA, Young DY, Fanburg-Smith JC. Melanoma markers in angiomyolipoma of the liver and kidney: a comparative study. Arch Pathol Lab Med. 2002;126:49-55.

132. Ren N, Qin LX, Tang ZY, Wu ZQ, Fan J. Diagnosis and treatment of hepatic angiomyolipoma in 26 cases. World J Gastroenterol. 2003;9:1856-8.

133. Högemann D, Flemming P, Kreipe H, Galanski M. Correlation of MRI and CT findings with histopathology in hepatic angiomyolipoma. Eur Radiol. 2001;11:1389-95.

134. Kudo M. Will Gd-EOB-MRI change the diagnostic algorithm in hepatocellular carcinoma? Oncology. 2010;78 Suppl 1:87-93.

135. Takahara M, Miyake Y, Matsumoto K, Kawai D, Kaji E, Toyokawa $\mathrm{T}$, et al. A case of hepatic angiomyolipoma difficult to distinguish from hepatocellular carcinoma. World J Gastroenterol. 2009;15: 2930-2.

136. Chung AY, Ng SB, Thng CH, Chow PK, Ooi LP. Hepatic angiomyolipoma mimicking hepatocellular carcinoma. Asian J Surg. 2002;25:251-4.

137. Prasad SR, Wang H, Rosas H, et al. Fat-containing lesions of the liver: radiologic-pathologic correlation. Radiographics. 2005;25: 321-31.

138. Yeh CN, Chen MF, Hung CF, et al. Angiomyolipoma of the liver. J Surg Oncol. 2001;77:195-200.

139. Yang CY, Ho MC, Jeng YM, Hu RH, Wu MY, Lee PH. Management of hepatic angiomyolipoma. J Gastrointest Surg. 2007;11:452-7.

140. Yuan-quan YU, Bing-Hong LOU, Hai-chao YAN, Ma R, Yuan-liang $\mathrm{XU}, \mathrm{Xu} \mathrm{J}-\mathrm{H}$, et al. Intrahepatic biliary cystadenoma presenting with pleural effusion. Chines Medical Journal. 2012;125(7):1355-7.

141. Devaney K, Goodman ZD, Ishak KG. Hepatobiliary cystadenoma and cystadenocarcinoma. A light microscopic and immunohistochemical study of 70 patients. Am J Surg Pathol. 1994;18:1078-91.

142. Kakar S, Burgart LJ. Tumours of the biliary system. Curr Diagn Pathol. 2005;11:34-43.

143. Koffron A, Rao S, Ferrario M, Abecassis M. Intrahepatic biliary cystadenoma: role of cyst fluid analysis and surgical management in the laparoscopic era. Surgery. 2004;136:926-36.

144. Thomas KT, Welch D, Trueblood A, Sulur P, Wise P, Gorden DL, et al. Effective treatment of biliary cystadenoma. Ann Surg. 2005;241:769-73.

145. Wanless IR. Micronodular transformation (nodular regenerative hyperplasia) of the liver: a report of 64 cases among 2,500 autopsies and a new classification of benign hepatocellular nodules. Hepatology. 1990;11:787-97.

146. Reshamwala PA, Kleiner DE, Heller T. Nodular regenerative hyperplasia: not all nodules are created equal. Hepatology. 2006;44:7.

147. Al-Mukhaizeem KA, Rosenberg A, Sherker AH. Nodular regenerative hyperplasia of the liver: an under-recognized cause of portal hypertension in haematological disorders. Am J Hematol. 2004;75: 225-30.

148. Wanless IR, Godwin TA, Allen F, Feder A. Nodular regenerative hyperplasia of the liver in hematologic disorders: a possible response to obliterative portal venopathy. A morphometric study of nine cases with an hypothesis on the pathogenesis. Medicine (Baltimore). 1980;59:367-79.

149. Breen DP, Marinaki AM, Arenas M, Hayes PC. Pharmacogenetic association with adverse drug reactions to azathioprine immunosuppressive therapy following liver transplantation. Liver Transpl. $2005 ; 11: 826-33$.

150. Nakanuma Y, Ohta G, Sasaki K. Nodular regenerative hyperplasia of the liver associated with polyarteritis nodosa. Arch Pathol Lab Med. 1984;108:133-5.

151. Reynolds WJ, Wanless IR. Nodular regenerative hyperplasia of the liver in a patient with rheumatoid vasculitis: a morphometric study suggesting a role for hepatic arteritis in the pathogenesis. J Rheumatol. 1984;11:838-42.

152. Colina F, Pinedo F, Solis JA, Moreno D, Nevado M. Nodular regenerative hyperplasia of the liver in early histological stages of primary biliary cirrhosis. Gastroenterology. 1992;102:1319-24.

153. Nakanuma Y, Ohta G. Nodular hyperplasia of the liver in primary biliary cirrhosis of early histological stages. Am J Gastroenterol. 1987;82:8-10.

154. Faust D, Fellbaum C, Zeuzem S, et al. Nodular regenerative hyperplasia of the liver: a rare differential diagnosis of cholestasis with response to ursodeoxycholic acid. Z Gastroenterol. 2003;41:255.

155. Nakanuma Y, Hoso M, Sasaki M, Terada T, Katayanagi K, Nonomura A, et al. Histopathology of the liver in non-cirrhotic portal hypertension of unknown aetiology. Histopathology. 1996;28:195-204.

156. Bonder A, Afdhal N. Evaluation of liver lesions. Clin Liver Dis. 2012;16(2):271-83.

157. El-Serag HB, Rudolph KL. Hepatocellular carcinoma: epidemiology and molecular carcinogenesis. Gastroenterology. 2007;132: 2557-76.

158. Parkin DM. Global cancer statistics in the year 2000. Lancet Oncol. 2001;2:533-43.

159. McGlynn KA, Tsao L, Hsing AW, Devesa SS, Fraumeni Jr JF. International trends and patterns of primary liver cancer. Int $\mathrm{J}$ Cancer. 2001;94:290-6.

160. Kirk GD, Lesi OA, Mendy M, et al. The Gambia Liver Cancer Study: infection with hepatitis B and C and the risk of hepatocellular carcinoma in West Africa. Hepatology. 2004;39:211-9.

161. Umemura T, Kiyosawa K. Epidemiology of hepatocellular carcinoma in Japan. Hepatol Res. 2007;37 Suppl 2:S95-S100.

162. Stroffolini T, Spadaro A, Di Marco V, Scifo G, Russello M, Montalto G, et al. Current practice of chronic hepatitis B treatment in Southern Italy. Eur J Intern Med. 2012;23(5):e124-7.

163. El-Serag HB, Mason AC. Rising incidence of hepatocellular carcinoma in the United States. N Engl J Med. 1999;340:745-50.

164. Bertino G, Ardiri A, Boemi PM, Calvagno GS, Ruggeri IM, Speranza A, et al. Epoetin alpha improves the response to antiviral treatment in HCV-related chronic hepatitis. Eur J Clin Pharmacol. 2010;66(10):1055-63. 